\title{
Advances in the Study of Fetal Development: From Descriptive to Dynamic Embryology
}

\section{Kohei Shiota}

\section{ABSTRACT}

Remarkable advances in medical imaging are facilitating the morphological study of early human prenatal development as well as the clinical assessment of normal and abnormal development during gestation. Classical descriptive embryology has been transformed into dynamic embryology and the interaction between basic embryology and clinical medicine is becoming more and more intimate. This paper describes an overview of the advances in the study of human embryonic and fetal development with special emphasis on the recent progress in embryo imaging.

Keywords: Human embryo, Human fetus, Imaging, visualization, Embryology, Clinical ultrasonography.

How to cite this article: Shiota K. Advances in the Study of Fetal Development-From Descriptive to Dynamic Embryology. Donald School J Ultrasound Obstet Gynecol 2012;6(2):171-178.

Source of support: Nil

Conflict of interest: None declared

\section{INTRODUCTION}

Human embryos and fetuses undergo drastic morphological changes (morphogenesis) during development. Morphogenesis in the developing embryo takes place in threedimensions, and the dimension of time is another important factor. Therefore, attempts have been made in embryological studies to visualize human prenatal development three- and four-dimensionally to describe dynamic ontogenetic events. Traditionally, major methods of studying developmental anatomy relied on histological sectioning of aborted embryos, and drawings and solid reconstruction from serial sections were used to demonstrate the structures of the embryonic body and organs. However, recent advances in imaging and computer technologies have enabled visualization of human prenatal development in highresolution three-dimensional (3D) and four-dimensional (4D) images.

On the other hand, remarkable progress has been made in clinical imaging, and various noninvasive diagnostic measures have been developed, such as computerized tomography (CT) and magnetic resonance (MR) imaging. In obstetric clinic, ultrasonography is widely used as an important tool of prenatal diagnosis which enables direct real-time visualization of the anatomy and activity of embryos and fetuses in utero.
In this paper, the advances in the study of human embryonic and fetal development are reviewed with special emphasis on the progress in visualization technologies.

\section{DESCRIPTIVE EMBRYOLOGY}

Historically, drawings and solid reconstructions were the major methods for demonstrating the 3D structures of the embryonic body. Very early studies in descriptive embryology were based on drawings of microscopic sections and graphic reconstructions, such as those developed by a German anatomist Wilhelm His. ${ }^{1-3}$ His built a drawing apparatus (the 'embryograph') for projecting microscopic sections and drawing them. He assembled 3D forms from microscopic sections and thereby established the basis of reconstruction (Fig. 1). His also adopted the wax-plate technique of reconstruction which was first introduced by Gustav Born. ${ }^{4}$ Born introduced the wax plate technique of reconstruction to human embryology and it was later modified in the Carnegie Laboratory in Baltimore by Osborne O Heard. ${ }^{5,6}$ Human embryos were embedded in paraffin or other embedding media and serially sectioned. The enlarged sections were drawn on wax plates of a specified thickness, the desired outlines were cut out, and the wax plates were stacked so as to produce solid reconstructions. Some of the historical reconstructed models of staged human embryos are now archived in the Human Developmental Anatomy Center in Washington, DC (http:/ /nmhm.washingtondc.museum/collections/hdac/index.htm) (Fig. 2). Based on those reconstructed models, precise drawings of staged human embryos and their organs were produced by skillful artists, including James F Didusch, which added greatly to the value of the Carnegie Collection of Human Embryos and promoted the understanding of human prenatal development (Fig. 3). Thus, solid reconstruction from serial sections and fine drawings based on reconstructed models were the primary imaging methods used in classic embryology.

However, such reconstruction and drawing methods are time-consuming and require special skills. Thanks to the advancement of computer technology during the last decades, computer-assisted reconstruction of biological structures became available. It has enabled the reconstruction of 3D structures from serial sections and to manipulate 


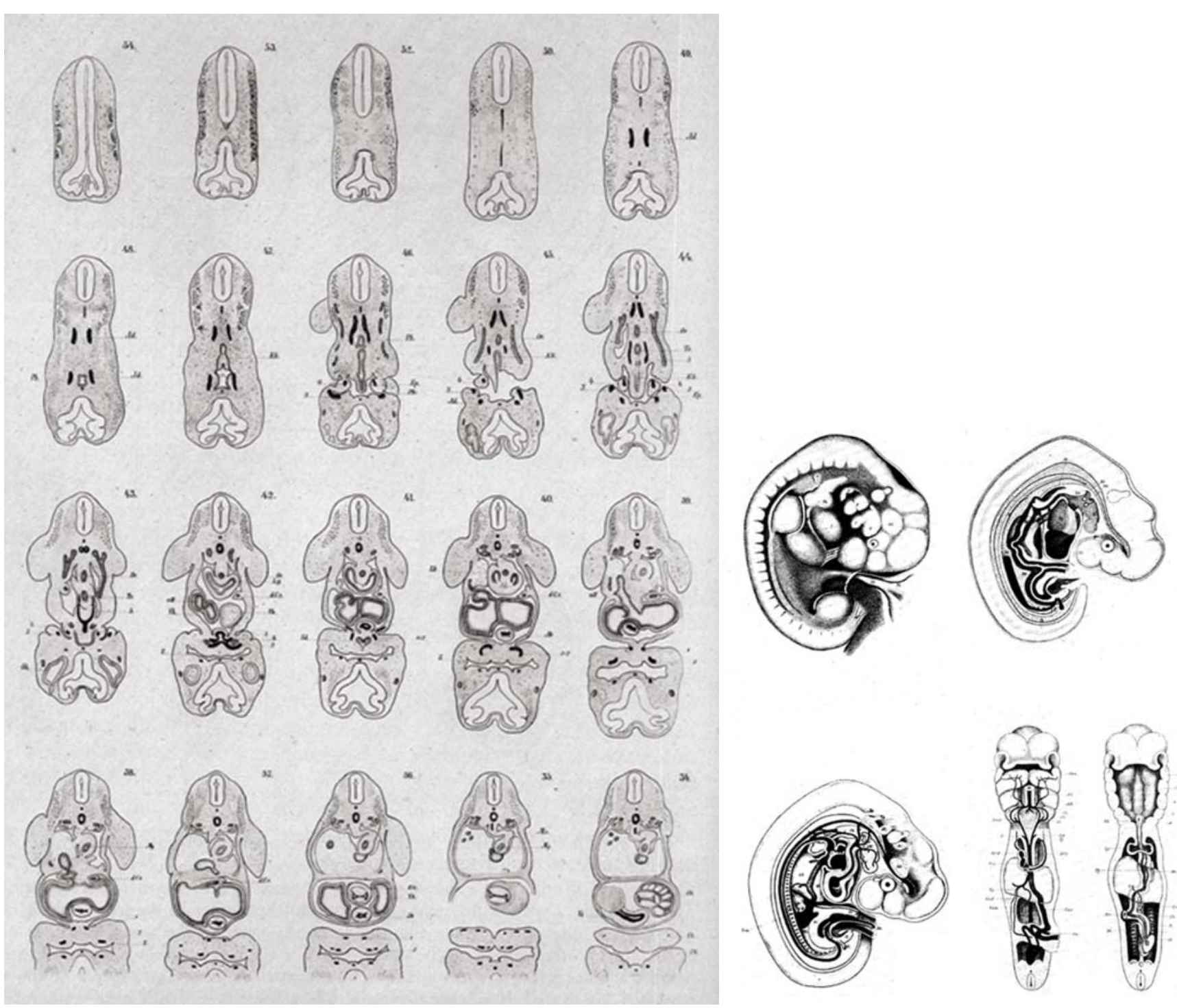

Fig. 1: The graphic method of Wilhelm His. Sketch of sequential sections (left) and graphic reconstructions of an embryo and its organs (right) (Adopted from His) ${ }^{1}$

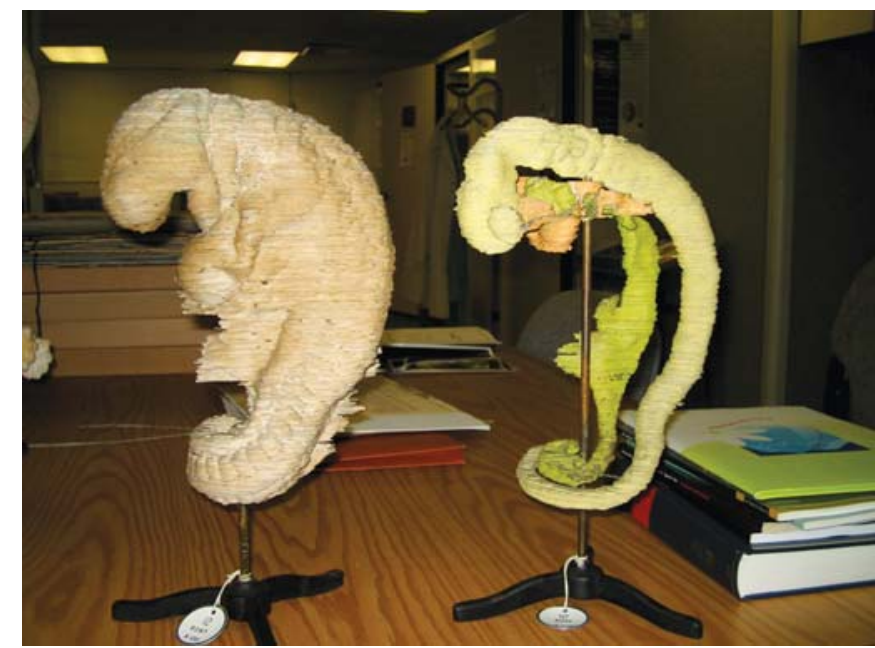

Fig. 2: Wax models of a Carnegie stage 13 embryo (left) and its internal organs (right) (Courtesy: The Human Developmental Anatomy Center, Washington, DC)

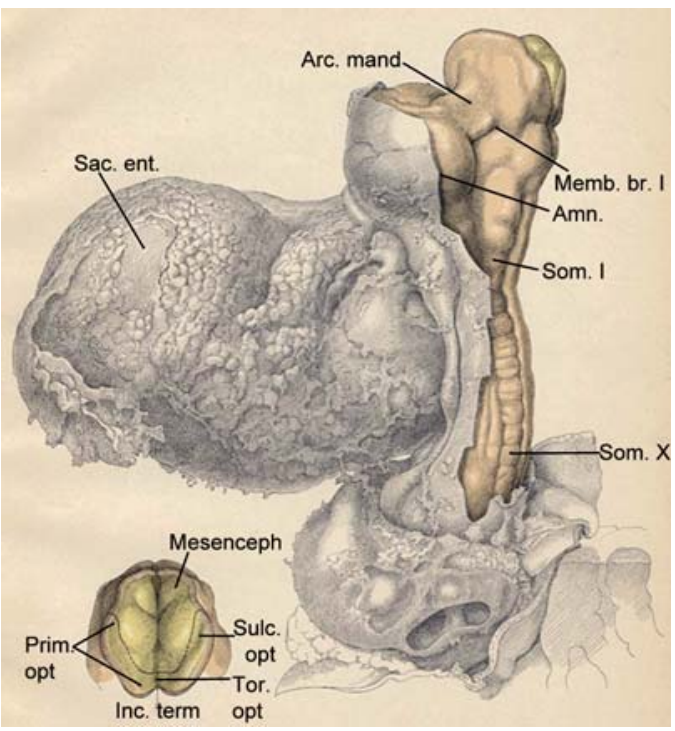

Fig. 3: Carnegie stage 10 embryo drawn by James Didusch (Contributions to Embryology 20:81, 1929) 


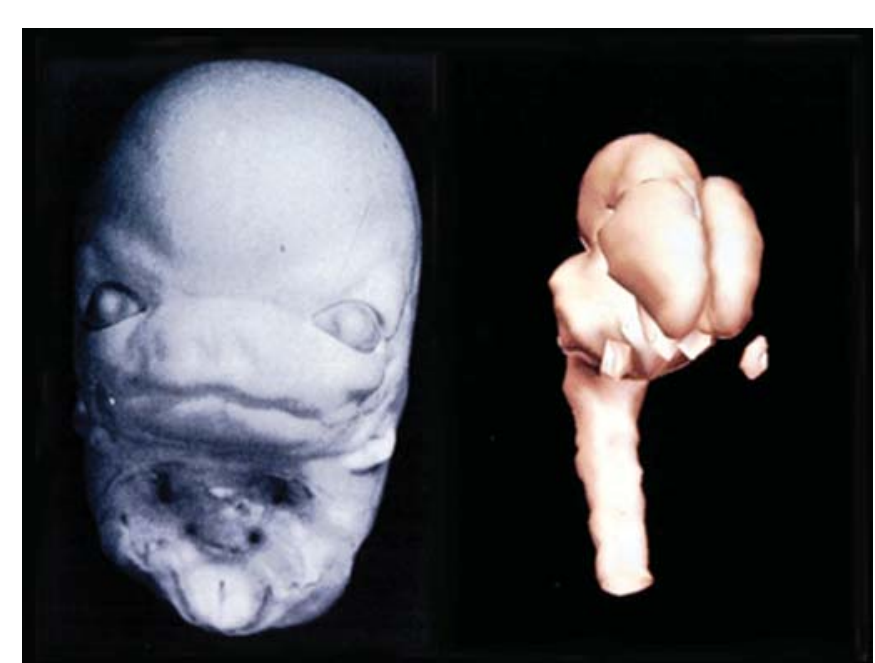

Fig. 4: The head of a Carnegie stage 21 embryo (left) and a computerized graphic model of its brain reconstructed from serial sections (Adopted from Shiota et al) ${ }^{7}$

reconstructed graphic images as desired on the viewing screen $^{7}$ (Fig. 4). However, the process still needs serial sectioning of specimens and intensive labor to acquire the desirable precision and refinement of the images.

The history of morphological studies to analyze human prenatal development was extensively reviewed by O’Rahilly.

\section{NEW TECHNOLOGIES FOR EMBRYO IMAGING}

Recently, remarkable progress has been made in nondestructive imaging technologies, such as computed tomography (CT) and magnetic resonance (MR) imaging. These techniques were developed as noninvasive diagnostic tools in clinical medicine, but technological advancement has enabled detailed imaging of tiny biological structures. ${ }^{9}$ Such imaging techniques do not require sectioning of the sample, and accurate 3D images can be generated with the aid of computer software.

\section{Computed Tomography (CT)}

CT has long been used in clinical medicine and is a powerful tool for visualizing hard tissues, such as bones and teeth. Recently, microfocus X-ray CT or micro-CT ( $\mu$-CT) has been applied to imaging relatively small structures, such as the fetal skull and inner ear to visualize their fine structures $^{10,11}$ (Fig. 5). With $\mu$-CT, it is possible to obtain serial $1024 \times 1024$ pixel tomograms. ${ }^{11} \mu$-CT is superior in imaging of hard tissues, but can image soft tissues to some extent. ${ }^{12}$ Some technical problems remain to be solved, including artifacts and noise, low contrast resolution and a relatively long exposure time. In addition, CT needs X-rays, which makes it difficult to use the CT apparatus in ordinary laboratories.

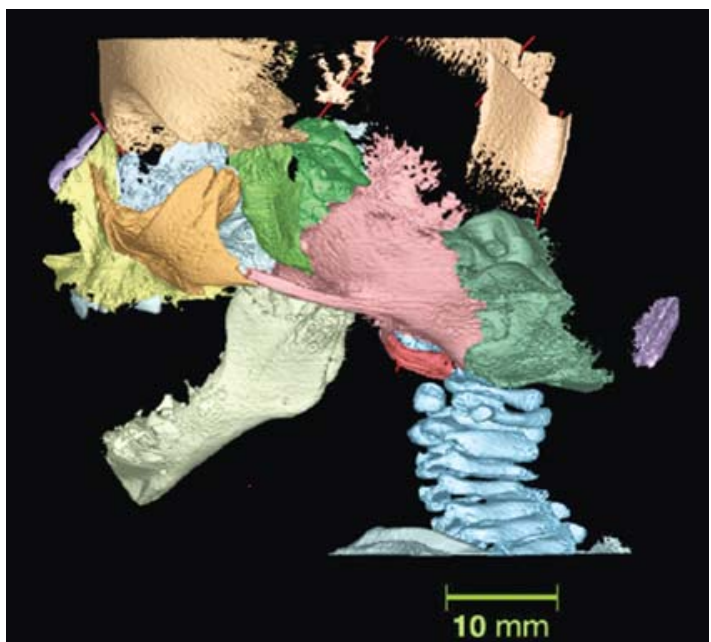

Fig. 5: A micro-CT image of the cranium of a 20-week fetus (Courtesy: Dr T Shibata)

\section{Magnetic Resonance (MR) Imaging}

The recent advances in MR microscopic technology has made it possible to scan and visualize relatively small samples. MR imaging is noninvasive and nondestructive and does not need sectioning of embryonic tissues. MR imaging was applied to the embryos of the human and laboratory animals by Smith et al., ${ }^{9,13,14}$ MR microscopy (MRM) has enabled tomographic imaging of tiny objects, and the digitized data can be manipulated to achieve 3D reconstruction of the samples. As MR images can be digitally resectioned in arbitrary planes, this allows seamless interrogation of anatomic structures in the embryo.

So far, imaging of embryos with superconducting magnets ranging from $1.5 \mathrm{~T}$ to $9 \mathrm{~T}$ has proven to be highly advantageous, providing the resolution of $40 \mu \mathrm{m} /$ pixel or better, which is equivalent to the resolution of lowmagnification histological sections and enables identifying various embryonic structures, such as the brain (and cerebral cortex), eyes, inner ears, pituitary gland, respiratory and digestive organs and gonads in embryos that are less than $30 \mathrm{~mm}$ in length ${ }^{15-17}$ (Fig. 6). Therefore, if MR microscopy is used for examination of human abortuses, it would help to identify internal visceral anomalies without dissection.

Initially, it took several hours to scan an embryo specimen that was only 10 to $20 \mathrm{~mm}$ long. This problem was overcome by the invention of a super-parallel MRM, ${ }^{18}$ which made it possible to image 4 to 8 specimens simultaneously and significantly facilitated the speed of imaging process. By using the novel super-parallel MR microscope, we have imaged over 1,400 human embryo specimens in a relatively short period of time ('Kyoto Human Embryo Visualization Project'). ${ }^{19,20}$ 

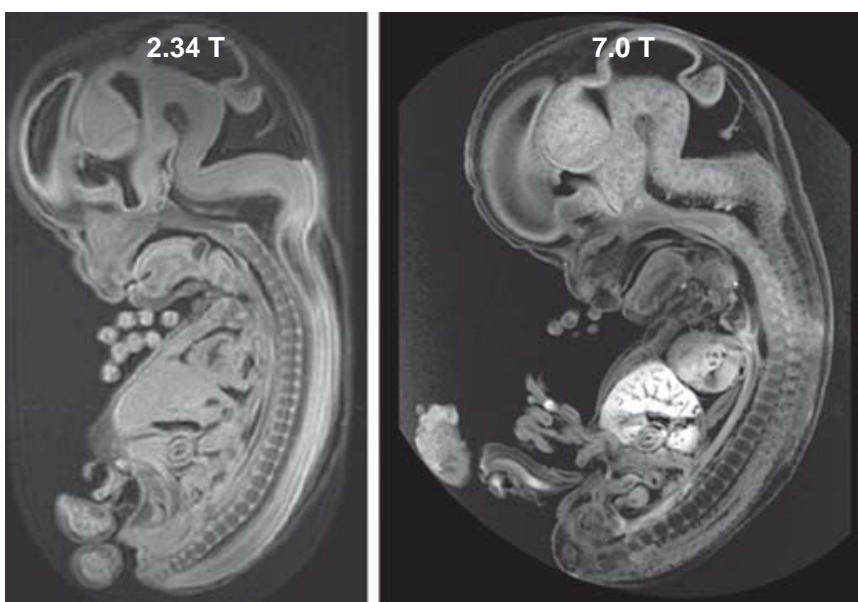

Fig. 6: Sagittal sectional MR images of 7-week human embryos. Left: 2.34 Tesla; Right: 7.0 Tesla (Courtesy: Drs K Kose and $S$ Yamada)

\section{Episcopic Fluorescence Image Capture}

Episcopic fluorescence image capture (EFIC) is another novel method that can provide registered 2D image stacks suitable for rapid 3D rendering. ${ }^{21}$ The sample is embedded in paraffin, and the paraffin block is sectioned using a sliding microtome. With each successive cut, the block face is photographed by epifluorescence imaging of tissue autofluorescence captured at the block face. Sudan red is incorporated in the paraffin wax in order to block fluorescence bleed through from deeper layers of the tissue. After each cut, the block is always returned to the same fixed photo-position, and thus the 2D image stacks generated are precisely registered. This allows for virtual resectioning of the sample in any imaging plane and also rapid highresolution 3D reconstruction of surface and internal structures. ${ }^{22,23}$

We acquired a series of EFIC images of staged human embryos and were successful to identify such fine structures as the glossopharyngeal and vagus nerves, vestibular and cochlear pouches and great vessels ${ }^{17}$ (Fig. 7). EFIC imaging is currently still higher in resolution and thus superior for imaging small specimens. The theoretical resolution in the
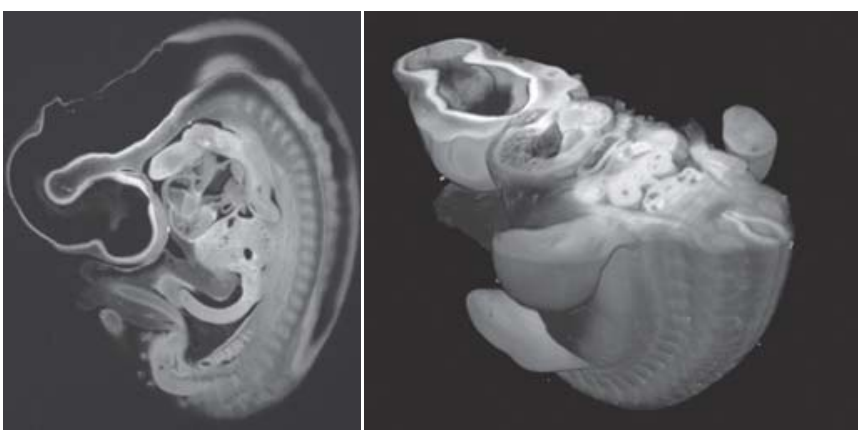

Fig. 7: A sagittal EFIC sectional image (left) and a reconstructed image (right) of a Carnegie stage 16 embryo (Courtesy: DrS Yamada)

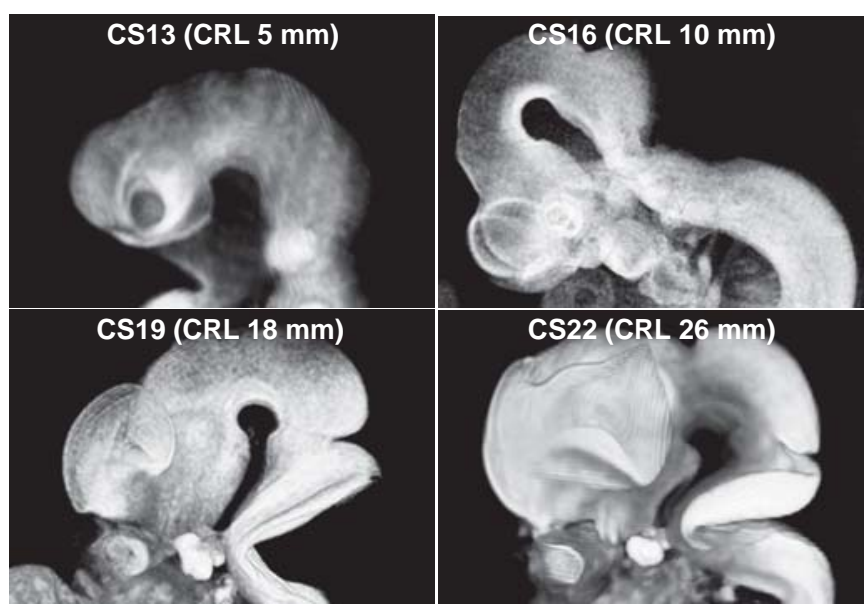

Fig. 8: Brains of human embryos reconstructed from EFIC sectiona data. CS: Carnegie stage; CRL: Crown-rump length (Courtesy: Dr S Yamada)

EFIC imaging ranges from 2 to $13 \mu \mathrm{m} / \mathrm{pixel}$, and the images provided are more refined than those obtained by MR imaging. It is possible to extract the image of the organ concerned and make 3D reconstruction (Fig. 8). A disadvantage of the EFIC method is that it needs sectioning of the sample and histological examination after sectioning is not easy.

\section{Optical Projection Tomography (OPT)}

Another technique for cross-sectional imaging was developed by Sharpe et $\mathrm{a}^{24}$ which is called optical projection tomography (OPT). Cross-sectional images are produced by scanning the specimen through the diode light beam coupled with a fiber-optic beam splitter. The apparatus is simpler than CT and MR and can image specimens with a thickness up to 15 to $20 \mathrm{~mm}$. However, the specimen to be imaged needs to be transparent to allow transmission of light and therefore cannot be examined histologically after OPT imaging.

\section{CLINICAL 3D ULTRASONOGRAPHY}

Observation of human embryos and fetuses in utero is quite important to evaluate their development, growth and wellbeing. A remarkable progress in prenatal diagnosis has been made since the introduction of sonographic visualization using a high frequency transvaginal transducer late in the last century. Now 3D and 4D ultrasounds combined with the transvaginal approach can provide accurate real-time information on the embryo and fetus in utero. Timor-Tritsch et $\mathrm{al}^{25}$ coined the term 'sonoembryology', which aims at organ-oriented investigation of human embryos and fetuses in utero by means of sonographic observation.

Sonography with high-resolution probes allows imaging of tiny structures in first-trimester embryos ${ }^{26,27}$ (Figs 9 to 11 ). Serial examination yields tomographic sectional 


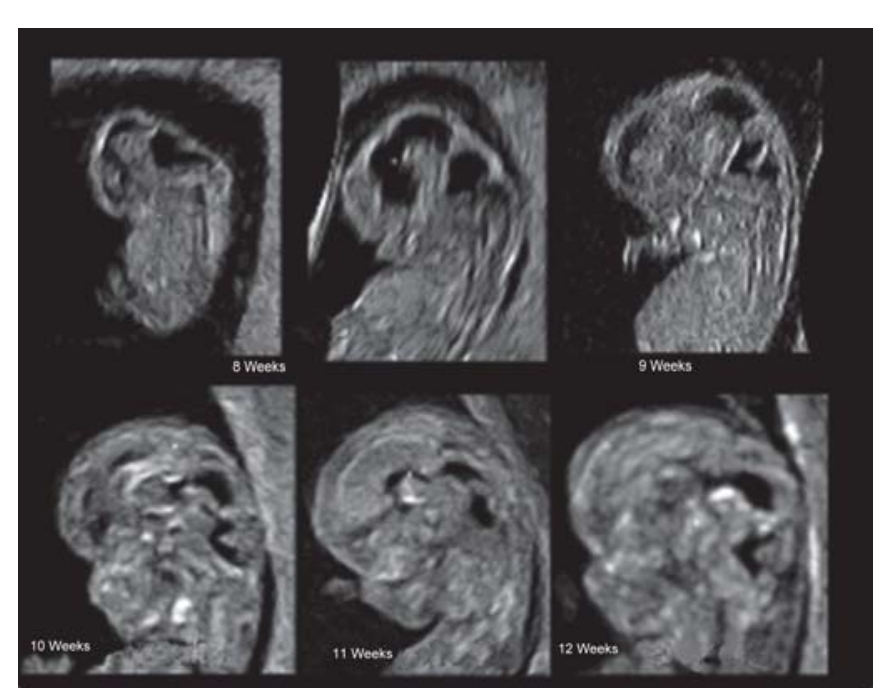

Fig. 9: Ultrasonographic images of the fetal head (Adopted from Pooh et al) ${ }^{27}$

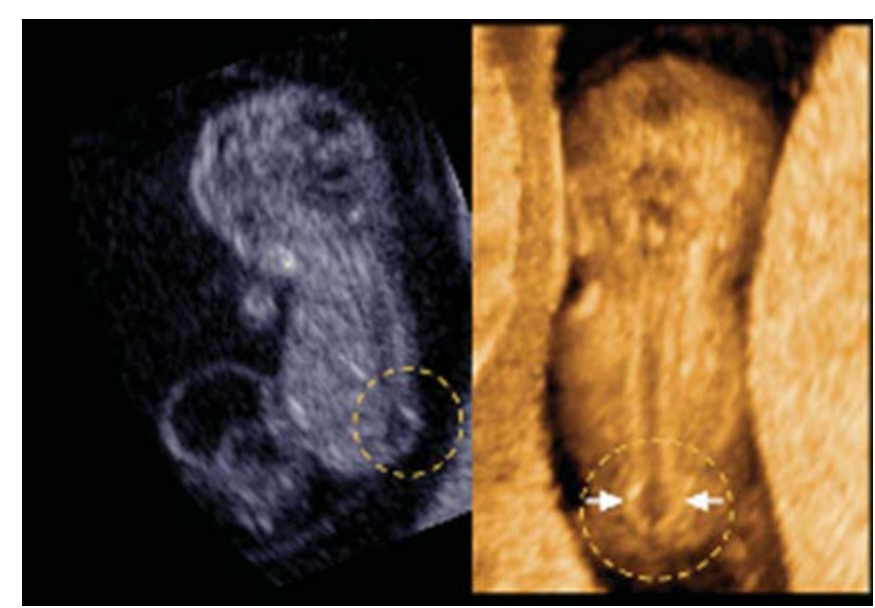

Fig. 10: Sagittal (left) and 3D (right) ultrasound images of a 9-week fetus showing a cystic dilatation in the lumbar area (Adopted from Pooh et al) ${ }^{27}$

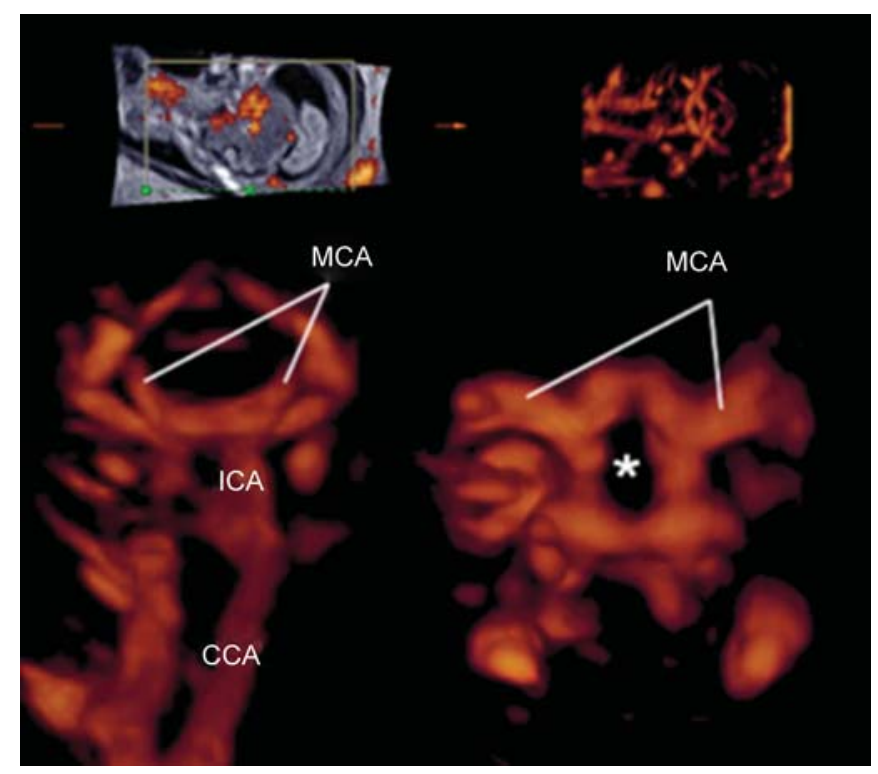

Fig. 11: A power Doppler image (upper left) and reconstructed 3D images of major brain arteries in a 12-week fetus. MCA: Middle cerebral artery; ICA: Internal carotid artery; CCA: Common carotid artery; Asterisk: Circle of Willis (Adopted from Pooh et al) ${ }^{27}$ images of fetal organs on desired planes, which makes it possible to document the changes in organs in question. For example, cerebral ventricular development was visualized using 3D inversion-rendering mode, ${ }^{28,29}$ showing that sonoembryology has become more sophisticated and objective.

In 1993 and 1994, the color Doppler technique was introduced by Kurjak et al and the detection and assessment of blood vessels in the early fetus became possible. ${ }^{30,31}$ Pooh and Aono $^{32}$ reported clear visualization by transvaginal power Doppler of the common carotid arteries, internal and external carotid arteries and middle cerebral arteries at 12 weeks of gestation. By using 3D power Doppler technology, the anatomy of major arteries can now be imaged clearly ${ }^{33}$ (Fig. 11).

The utilization of postprocessing algorithms, such as the maximum mode, can be used to demonstrate the fetal skeleton. Chaoui et $\mathrm{al}^{34}$ reported clear 3D images of the fetal cranium and was successful to identify an abnormally wide metopic suture during the second trimester of pregnancy.

3D ultrasonography is an extremely powerful tool for prenatal diagnosis of structural anomalies. Such diagnosis is possible in the first and second trimesters of pregnancy, depending on the type and severity of the defect. Often various anomalies are identified in embryos and fetuses without abnormal nuchal translucency. Therefore, ultrasonography is now indispensable for prenatal diagnosis in obstetric clinic.

\section{HUMAN DEVELOPMENTAL ATLASES AND MORPHOLOGICAL DATABASES}

3D and 4D visualization to illustrate human prenatal development has been attemted for research and educational purposes. A project called the ‘Visible Embryo’ project was carried out at the US National Museum of Health and Medicine (NMHM). ${ }^{35}$ It utilized human embryo specimens from the Carnegie Embryological Collection and digitized 3D datasets of staged human embryos were completed which are now partly accessible on the web (URL: http:// www.visembryo.com/baby/).

After the Visible Embryo project was discontinued in 2003, the Virtual Human Embryo project was initiated by RF Gasser and RJ Cork, which was supported by the National Institute of Child Health and Human Development (NICHHD) and the National Library of Medicine (URL: http://virtualhumanembryo.lsuhsc.edu/). The database consists of the DREM (digitally reproduced embryonic morphology) and HEIRLOOM (human embryo imaging and reconstruction, library online media) components. 
The DREM database contains high resolution microscopic morphology of human embryos with the level of each section image shown on 3D reconstructions. The HEIRLOOM project contains $3 \mathrm{D}$ reconstructions of the systems of the same Carnegie specimens and assembles an index of terms designed to provide the stage and section locations of many structures in the DREM series.

In Kyoto, we have scanned over 1,400 staged human embryos either by MR microscopy or EFIC ('Kyoto Human Embryo Visualization Project') which was funded by the Japan Science and Technology Agency. ${ }^{19,20}$ Selected images from the database can be viewed on the web (URL: http:// bird.cac.med.kyoto-u.ac.jp/index_e.html).

Recently, another web-based Human Embryo Atlas spanning Carnegie stage CS 13 to 23 was generated using the MR and EFIC data (URL: http://apps.devbio.pitt.edu/ humanatlas). For each developmental stage, EFIC and MR imaging stacks of serial 2D images are presented as QuickTime movies in three orthogonal views that correspond to the standard sagittal, frontal and transverse histological planes. In addition, selected 3D reconstructions are included in the atlas as QuickTime movies or as interactive QTVRs. Viewing 2D image stacks as a video sequence via the QuickTime movies allows easy tracing of rapidly changing anatomic structures in the embryo, such as the rapidly evolving embryonic circulation. For example, the aortic and pulmonary outflow tracts from the heart can be seen to connect with the descending aorta and umbilical artery, followed by return via the umbilical vein to the embryonic circulation. ${ }^{17}$

Such human embryo atlases will be useful for clinicians and researchers studying human embryonic development and pathogenesis of human birth defects. In addition, such atlases will be valuable teaching tools for human embryology and teratology. Especially, web-accessible human embryo atlases should serve as valuable tutorials of human developmental anatomy. ${ }^{19,36-40}$ Some website has an interactive function for users to propose new annotations or revisions of existing contents to make it a more accurate and valuable tool for research and education. ${ }^{17}$

\section{THE FUTURE}

In the 'postsequence' era, it is becoming important to investigate the functions of genes and their interactions in the organism, which cannot be elucidated by conventional molecular biological techniques. To analyze the dynamic functions and network of developmental genes, it is necessary to visualize their 3D and 4D expression patterns in the embryo. The data of gene expression in embryonic tissues obtained by in situ hybridization in sections and whole-mount samples can be mapped in 3D images of the embryo, and their sequential expression patterns can be analyzed. Such databases of developmental gene expression would help to unravel the yet unknown functions, pathways, and interaction of multiple genes in normal and abnormal development. Some 3D databases of developmental gene expression are being furnished for mouse embryos by groups at the University of Edinburgh and MRC (EMAP and EMAGE), ${ }^{41}$ the University of Vienna (GeneEMAC) ${ }^{42}$ and the Jackson Laboratory (GXD). ${ }^{43}$ It is hoped that a similar database for human embryos will enable the comparison of developmental gene expression patterns in human and laboratory animals and provide a clue to identifying new gene functions in the human embryos as well as gene mutations responsible for human birth defects.

Sequential 3D images of human embryos also have the potential to serve as a reference and an important data resource for human developmental studies similar to the Visible Human database that contains digitized serial cross-sectional images of normal male and female adult bodies ${ }^{44,45}$ (URL: http:// www.nlm.nih.gov/research/visible/visible_human.html). They could serve as models of network-accessible digital image libraries for medical research and education. Actually, various new research projects have emerged from the Visible Human Project, such as the invention of internet-enabled visualization tools and navigation technologies for anatomy education and research; establishing comprehensive atlases of the human body for clinical imaging diagnosis; and virtual reality and surgical simulation for health care education and training. ${ }^{46}$ Similarly, 3D visualization of human embryonic development should be useful in biomedical research and education because such images and movie-illustration of sequential developmental changes would help researchers and students to understand the dynamic morphogenetic movements visually that occur in three- and four-dimensions (Fig. 12).

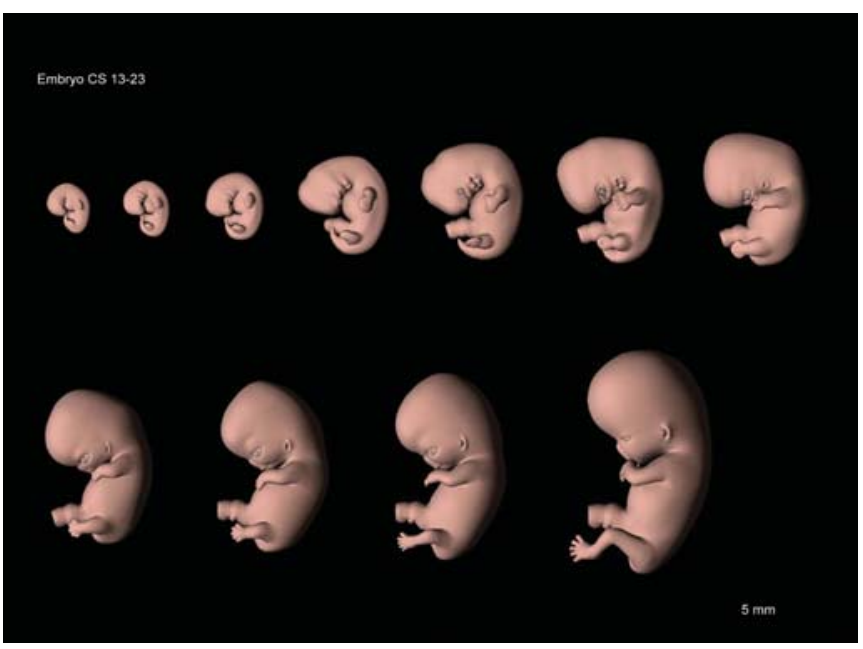

Fig. 12: Computer graphic models of staged human embryos reconstructed from MR sectional images (Adopted from Yamada et al) ${ }^{19}$ 


\section{REFERENCES}

1. His W. Anatomie menschlicher Embryonon. Leipzig: Vogel 1880.

2. His W. Über die Methoden der plastischen Rekonstruktion und über deren Bedeutung für Anatomie und Entwicklungsgeschichte. Anat Anz 1887;2:382-94.

3. His W. Die Entwicklung des menschlichen Gehirns wärend der ersten Monate. Leipzig: Hirzel 1904.

4. Born G. Die Plattenmodelliermethode. Arch Mikr Anat 1883; 22:584-99.

5. Heard OO. A photographic method of orienting serial sections for reconstruction. Anat Rec 1931;49:59-70.

6. Heard OO. Methods used by $\mathrm{CH}$. Heuser in preparing and sectioning early embryos. Contrib Embryol Carnegie Inst 1957; 36:1-18.

7. Shiota K, Nakatsu T, Irie H. Computerized three-dimensional reconstruction of normal and holoprosencephalic human embryos. Birth Defects: Orig Art Ser 1993;29(1):253-63.

8. O’Rahilly R. One hundred years of human embryology. In: Kalter H (Ed). Issues and Reviews in Teratology. New York: Plenum Press 1988;4:81-128.

9. Smith BR. Visualizing human embryos. Sci Am 1999;280: 76-81.

10. Shibata T, Nagano T. Applying very high resolution microfocus $\mathrm{X}$-ray CT and 3D reconstruction to the human auditory apparatus. Nat Med 1996;2:933-35.

11. Shibata T, Matsumoto S, Nagano T, Sasaki H. Micro-focus $\mathrm{X}$-ray computed tomography images of the 3D structure of the cranium of a fetus with asymmetric double malformation. Congenit Anom (Kyoto) 2006; 46:10-15.

12. Shibata T, Matsumoto S, Agishi T, Nagano T. Visualization of Reissner membrane and the spiral ganglion in human fetal cochlea by micro-computed tomography. Am J OtolaryngolHead Neck Med Surg 2009;30:112-20.

13. Smith BR, Johnson GA, Groman EV, Linney E. Magnetic resonance microscopy of mouse embryos. Proc Natl Acad Sci USA 1994;91:3530-33.

14. Smith BR, Linney E, Huff DS, Johnson GA. Magnetic resonance microscopy of embryos. Comput Med Imaging Graph 1996; 20:483-90.

15. Haishi T, Uematsu T, Matsuda Y, Kose K. Development of a 1.0 T MR microscope using a Nd-Fe-B permanent magnet. Magn Reson Imaging 2001;19:875-80.

16. Effmann EL, Johnson GA, Smith BR, Talbott GA, Cofer G. Magnetic resonance microscopy of chick embryos in ovo. Teratology 1988;38:59-65.

17. Yamada S, Samtani RR, Lee ES, Lockett E, Uwabe C, Shiota $\mathrm{K}$, et al. Developmental atlas of the early first trimester human embryo. Dev Dyn 2010;239:1585-95.

18. Matsuda Y, Utsuzawa S, Kurimoto T, Haishi T, Yamazaki Y, Kose K, et al. Super-parallel MR microscope. Magn Reson Med 2003;50:183-89.

19. Yamada S, Uwabe C, Nakatsu-Komatsu T, Minekura Y, Iwakura M, Motoki T, et al. Graphic and movie illustrations of human prenatal development and their application to embryological education based on the human embryo specimens in the Kyoto Collection. Dev Dyn 2006;235:468-77.

20. Shiota K, Yamada S, Nakatsu-Komatsu T, Uwabe C, Kose K, Matsuda Y, et al. Visualization of human prenatal development by magnetic resonance imaging (MRI). Am J Med Genet A 2007;143A:3121-26.
21. Weninger WJ, Mohun T. Phenotyping transgenic embryos: A rapid 3D screening method based on episcopic fluorescence image capturing. Nat Genet 2002; 30:59-65.

22. Rosenthal J, Mangal V, Walker D, Bennett M, Mohun TJ, Lo CW. Rapid high resolution three-dimensional reconstruction of embryos with episcopic fluorescence image capture. Birth Defects Res C Embryo Today 2004;72:213-23.

23. Weninger WJ, Meng S, Streicher J, Müller GB. A new episcopic method for rapid 3D reconstruction: Applications in anatomy and embryology. Anat Embryol (Berl) 1998;197:341-48.

24. Sharpe J, Ahlgren U, Perry P, Hill B, Ross A, HecksherSorensen J, et al. Optical projection tomography as a tool for 3D microscopy and gene expression studies. Science 2002;296: 541-45.

25. Timor-Tritsch IE, Peisner DB, Raju S. Sonoembryology: An organ-oriented approach using a high-frequency vaginal probes. J Clin Ultrasound 1990;18:286-98.

26. Pooh RK. Neuroanatomy visualized by 2D and 3D. In: Pooh RK, Kurjak A (Eds). Fetal Neurology. St Louis: Jaypee Brothers Medical Publlishers 2009;16-38.

27. Pooh RK, Shiota K, Kurjak A. Imaging of the human embryo with magnetic resonance imaging microscopy and highresolution transvaginal three-dimensional sonography: Human embryology in the 21st century. Am J Obstet Gynecol 2011; 204:77.e1-16.

28. Kim MS, Jeanty P, Turner C, Benoit B. Three-dimensional sonographic evaluations of embryonic brain development. J Ultrasound Med 2008;27:119-24.

29. Hata T, Dai SY, Kanenishi K, Tanaka H. Three-dimensional volume-rendered imaging of embryonic brain vesicles using inversion mode. J Obstet Gynaecol Res 2009;35:258-61.

30. Kurjak A, Zudenigo D, Predanic M, Kupesic S. Recent advances in the Doppler study of early fetomaternal circulation. J Perinat Med 1993;21:419-39.

31. Kurjak A, Schulman H, Predanic A, Predanic M, Kupesic S, Zalud I. Fetal choroid plexus vascularization assessed by color flow ultrasonography. J Ultrasound Med 1994;13:841-44.

32. Pooh RK, Aono T. Transvaginal power Doppler angiography of the fetal brain. Ultrasound Obstet Gynecol 1996;8:417-21.

33. Pooh RK, Kurjak A, Tikvica A. Normal and abnormal brain vascularity. In: Pooh RK, Kurjak A (Eds). Fetal Neurology. St Louis: Jaypee Brothers Medical Publlishers 2009;39-58.

34. Chaoui R, Levaillant JM, Benoit B, Faro C, Wegrzyn P KH. Three-dimensional sonographic description of abnormal metopic suture in second- and third-trimester fetuses. Ultrasound Obstet Gynecol 2005;26:761-64.

35. Cohen J. Embryo development at the click of a mouse (News of the week). Science 2002; 297:1629.

36. Watt ME, McDonald SW, Watt A. Computer morphing of scanning electron micrographs: An adjunct to embryology teaching. Surg Radiol Anat 1996;18:329-33.

37. Aiton JF, McDonough A, McLachlan JC, Smart SD, Whiten SC. World Wide Web access to the British Universities Human Embryo Database. J Anat 1997;190:149-54.

38. Carlson BM. Embryology in the medical curriculum. Anat Rec 2002; 269:89-98.

39. Puerta-Fonolla J, Vazquez-Osorio T, Ruiz-Cabello J, MurilloGonzalez J, Pena-Melian A. Magnetic resonance microscopy versus light microscopy in human embryology teaching. Clin Anat 2004;17:429-35.

40. Arroyo-Jimenez Mdel M, Marcos P, Martinez-Marcos A, Artacho-Perula E, Blaizot X, Munoz M, et al. Gross anatomy 
dissections and self-directed learning in medicine. Clin Anat 2005;18:385-91.

41. Baldock RA, Bard JB, Burger A, Burton N, Christiansen J, Feng $\mathrm{G}$, et al. EMAP and EMAGE: A framework for understanding spatially organized data. Neuroinformatics 2003;1: 309-25.

42. Streicher J, Donat MA, Strauss B, Sporle R, Schughart K, Muller GB. Computer-based three-dimensional visualization of developmental gene expression. Nat Genet 2000;25:147-52.

43. Smith CM, Finger JH, Hayamizu TF, McCright IJ, Eppig JT, Kadin JA, et al. The mouse Gene Expression Database (GXD): 2007 update. Nucleic Acids Res 2007;35:D618-23 (database issue).

44. Ackerman MJ. The visible human project: A resource for anatomical visualization. Medinfo 1998; 9:1030-32.
45. Ackerman MJ. The visible human project: A resource for education. Acad Med 1999; 74:667-70.

46. Ackerman MJ, Yoo T, Jenkins D. From data to knowledge: The visible human project continues. Medinfo 2001;10: 887-90.

\section{ABOUT THE AUTHOR}

\section{Kohei Shiota (Corresponding Author)}

Department of Anatomy and Developmental Biology, Congenital Anomaly Research Center, Kyoto University Graduate School of Medicine, Kyoto, Japan, Phone: (+81)75-753-2217, Fax: (+81) 75753-5546, e-mail: shiota@hq.kyoto-u.ac.jp 